\title{
Myhre syndrome
}

INSERM

\section{Source}

INSERM. (1999). Orphanet: an online rare disease and orphan drug data base. Myhre syndrome. ORPHA:2588

Myhre syndrome is characterised by striking muscular build, short stature, reduced joint mobility, brachydactyly, mixed hearing loss and mental retardation of variable severity. Facial dysmorphism with short palpebral fissures, short philtrum, thin lips, maxillary hypoplasia and prognathism is present. Thick skin has been observed in six patients. 